\title{
Epigenetic Guardian: A Review of the DNA Methyltransferase DNMT3A in Acute Myeloid Leukaemia and Clonal Haematopoiesis
}

\author{
Sabah F. Chaudry and Timothy J. T. Chevassut \\ Brighton and Sussex Medical School, University of Sussex, Brighton, East Sussex BN1 9PS, UK \\ Correspondence should be addressed to Timothy J. T. Chevassut; t.chevassut@bsms.ac.uk
}

Received 28 July 2016; Revised 18 October 2016; Accepted 14 November 2016; Published 14 February 2017

Academic Editor: Heide Schatten

Copyright (c) 2017 Sabah F. Chaudry and Timothy J. T. Chevassut. This is an open access article distributed under the Creative Commons Attribution License, which permits unrestricted use, distribution, and reproduction in any medium, provided the original work is properly cited.

\begin{abstract}
Acute myeloid leukaemia (AML) is a haematological malignancy characterized by clonal stem cell proliferation and aberrant block in differentiation. Dysfunction of epigenetic modifiers contributes significantly to the pathogenesis of AML. One frequently mutated gene involved in epigenetic modification is DNMT3A (DNA methyltransferase-3-alpha), a DNA methyltransferase that alters gene expression by de novo methylation of cytosine bases at $\mathrm{CpG}$ dinucleotides. Approximately $22 \%$ of AML and $36 \%$ of cytogenetically normal AML cases carry DNMT3A mutations and around $60 \%$ of these mutations affect the R882 codon. These mutations have been associated with poor prognosis and adverse survival outcomes for AML patients. Advances in whole-exome sequencing techniques have recently identified a large number of DNMT3A mutations present in clonal cells in normal elderly individuals with no features of haematological malignancy. Categorically distinct from other preleukaemic conditions, this disorder has been termed clonal haematopoiesis of indeterminate potential (CHIP). Further insight into the mutational landscape of CHIP may illustrate the consequence of particular mutations found in DNMT3A and identify specific "founder" mutations responsible for clonal expansion that may contribute to leukaemogenesis. This review will focus on current research and understanding of DNMT3A mutations in both AML and CHIP.
\end{abstract}

\section{DNA Methylation}

1.1. Epigenetic Modifications. Normal haematopoiesis is one of many cellular processes regulated by epigenetic modification. Haematopoietic stem cells (HSCs) are required to proliferate, differentiate, and mature in a controlled fashion down various distinct myeloid and lymphoid lineages giving rise to terminally differentiated blood cells. Due to the varied number of lineages that can arise from haematopoietic stem cells, dysfunction produces an assortment of disease phenotypes. Aberrant expressions of epigenetic regulators are increasingly recognised as being central to this process.

Two major forms of epigenetic regulation are recognised. DNA methylation involves direct modification of the DNA molecule itself via the addition of a methyl group to cytosine bases, generally at $\mathrm{CpG}$ dinucleotides, without any actual alteration of the DNA sequence itself, changing how the
DNA is read and influencing the level of expression of the gene. A second level of epigenetic regulation occurs at the level of the histones which can undergo various chemical modifications including methylation, phosphorylation, and acetylation, thereby influencing local transcriptional activity. In this report, we discuss DNA methylation and its role in haematopoiesis and haematological malignancy with particular focus on DNMT3A.

1.2. DNA Methylation. DNA methylation is an important process involved in developmental patterning, chromatin modification, and imprinting. Aberrant methylation has long been recognised to have a role in disease processes such as cancer $[1,2]$. As Figure 1 shows, methylation involves the addition of a methyl group $\left(\mathrm{CH}_{3}\right)$ to specific cytosines base found in the DNA sequence to produce 5-methylcytosine $(5 \mathrm{mC})[3]$. 


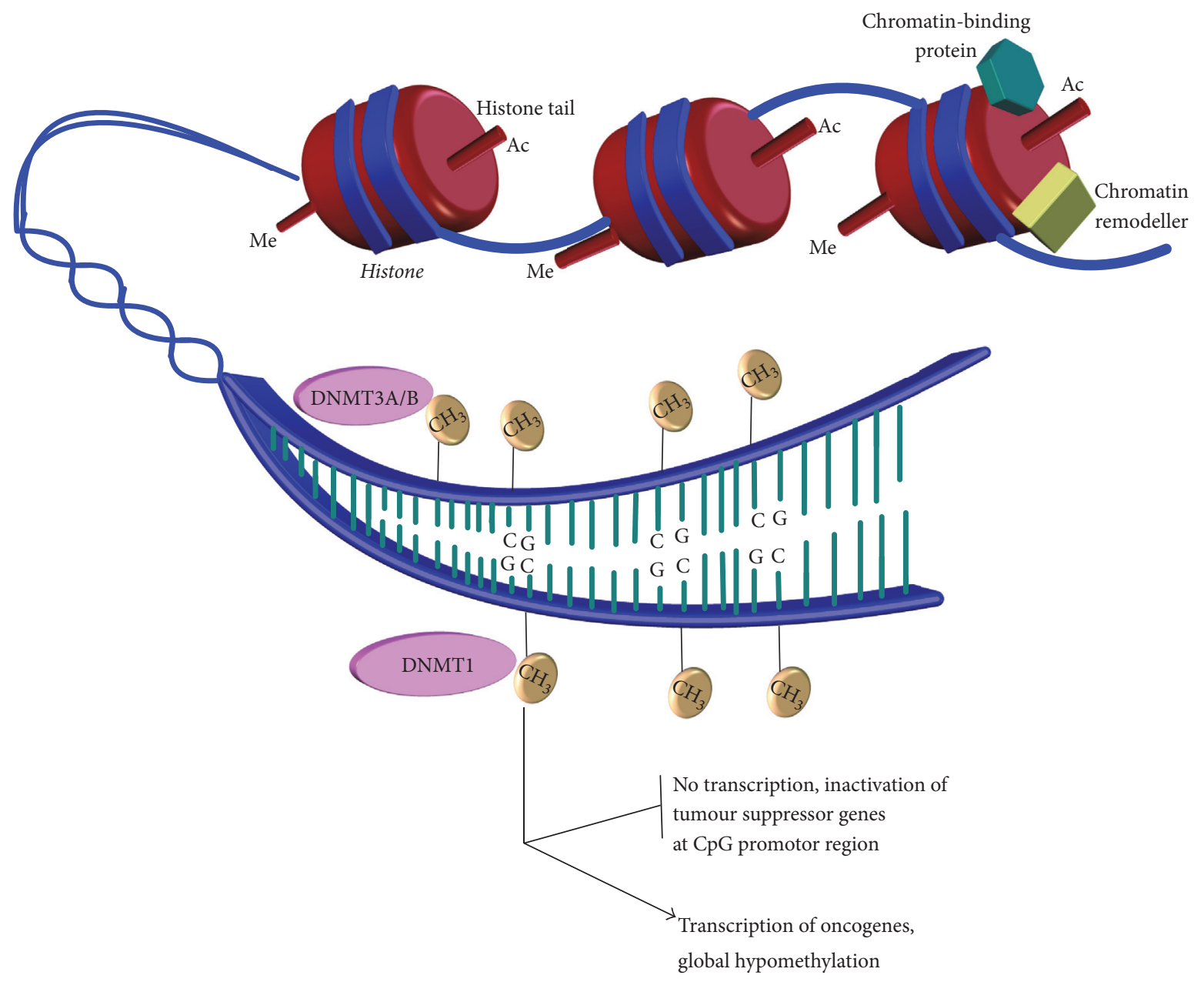

FIGURE 1: DNA methylation by DNA methyltransferase enzymes. An illustration showing the positively charged histones binding the negatively charged DNA into compact chromatin to prevent gene transcription. The figure shows how other proteins can interact with histones to regulate transcription of genes. Modifications of histones tails such as acetylation and methylation change chromatin architecture, unwinding chromatin to allow access to the DNA sequence. Several other proteins, including chromatin remodellers, can also affect chromatin architecture. Regulators such as DNA methyltransferase enzymes are then able to access DNA to add methyl groups $\left(\mathrm{CH}_{3}\right)$ to appropriate cytosine bases. The methyl group is added to the $\mathrm{C} 5$ position of the pyrimidine ring to produce 5 -methylcytosine (5mC). Aberrant methylation as illustrated can inactivate tumor suppressor genes (through hypermethylation) and increase expression of oncogenes (through hypomethylation of promotor sites of these genes), both of which can contribute to leukaemogenesis.

Methylation occurs at sites in the genome where the cytosine base is bound to the adjacent guanine base by a phosphodiester bond. These sites are referred to as CpG residues and human genes have approximately $60-80 \%$ of these individual CpGs methylated [4]. However, clustered CpG residues in "islands" are often located near gene promoter regions and are predominantly nonmethylated [4]. This allows for important regulation of gene expression. While highly studied, the purpose and function of these DNA methylated promotor sites are not well understood. Previous studies have highlighted that the density of $\mathrm{CpG}$ residues have been consequently related to methylation levels. Promoter sites that are poorly populated with $\mathrm{CpG}$ residues are seen to be highly methylated, while the opposite has been observed in promotor sites with highly populated $\mathrm{CpG}$ residues [5]. While studies have suggested a correlation between promoter methylation and transcriptional activity, with methylated promoters often being transcriptionally silent $[4,6-9]$, it is not clear that DNA methylation itself is responsible for gene silencing, and rather regulation of gene expression through DNA methylation may be far more complex.

New methods in genome-wide mapping have allowed for further insight into the role of gene regulation by DNA methylation. A growing body of evidence suggests that, rather than working in isolation, DNA methylation could possibly be intertwined with other gene silencing mechanisms. Work specifically looking at the modulation of chromatin has produced various theories on the functional role of $\mathrm{CpG}$ island methylation at promotor sites in respect to gene expression. One hypothesis surrounding the role of DNA methylation is that it may modulate polycomb protein targeting [10]. Several studies gave early indications that PRC2 (polycomb 
repressor complex 2) played a key role by observing that PRC2 components were binding to CpG islands [11-13]. Specifically the histone marker H3K27me3, a trimethylated histone, has been used in studies as a signature of PRC2 activity and has also been identified to cause gene silencing through several mechanisms [14]. Interestingly, a negative correlation has been suggested to exist between DNA methylation, $\mathrm{H} 3 \mathrm{~K} 27 \mathrm{me} 3$, and $\mathrm{CpG}$ high density regions $[15,16]$. This has led to the theory that DNA methylation may negatively regulate the targeting of polycomb proteins [10]. Data to support this is still correlative, where global levels of hypomethylation are associated with increased PRC2 binding $[11,14,15]$, but further work is needed to establish the temporal and spatial relationship between DNA methylation and polycomb targeting and regulation of gene expression.

Though the canonical regulation of promotor sites by methylation is an important phenomenon observed in $\mathrm{X}$ chromosome inactivation and imprinting $[1,17]$, the actual role of methylation in developmental processes and embryonic patterning is not well understood. While hypomethylated promotor sites are found to be present at important germline specific genes during development, these genes are also found to be methylated in somatic cells [5]. Though studies have shown that the absence of methylation in mouse embryo models have led to the activation of specific genes $[18,19]$, it is unclear whether the methylation process itself is directly involved in gene silencing in embryonic patterning and highlights the complex role of methylation in developmental processes. Methylation of nonpromoter regions appears to be largely irreversible and this epigenetic memory and irreversibility are an important property of gene silencing in early development to produce monoallelic expression of specific genes [20]. In contrast to this, plasticity of methylation patterns at promotor sites has been suggested to regulate cellular properties such as pluripotency in HSCs to prevent uncontrolled differentiation [18, 20, 21].

The identification of areas flanking CpG islands, called "shores" and "shelves," adds further complexity to the regulation of gene expression. Shores are identified as being $0-2 \mathrm{~kb}$ away from islands, while shelves are 2-4 kb away; furthermore, "open sea" sites, which are spread throughout the genome itself, have also been identified [22, 23]. Aberrant levels of hypomethylation and hypermethylation of these shores, shelves, and open sea sites have been associated with several malignant processes [2]. However, the significance of such areas and the pattern of methylation observed in these disease processes at these sites is still unclear. Recent studies investigating HSCs have identified hypomethylated regions referred to as "canyons" [24]. These canyons may overlap CpG islands but are characteristically distinct from low-methylated islands [24]. Canyons are seen to be conserved across cell types and species. Genes associated with haematopoiesis are reported to be enriched in canyons and are vulnerable to methylation dysfunction observed in haematological malignancy [24].

Global hypomethylation and associated overall genomic instability in DNA elements such as exons, introns, and transposons have been suggested to have a role in disease processes $[9,25]$. Altered levels of methylation have been associated with instability of microsatellite repeats; dysfunction of such repeat elements is well characterized in diseases such as Huntington's disease and cancer [9]. In addition to hypomethylated promotor sites being transcriptionally active, global hypomethylation has also been associated with the activation of new enhancer sites, similarly resulting in gene upregulation [26].

1.3. DNA Methyltransferase (DNMT) Enzymes. DNA methylation is carried out by a family of DNA methyltransferase enzymes, which include DNMT1, DNMT3A, and DNMT3B. Figure 2 illustrates the structure of these genes. By contrast, DNMT3L has no catalytic domain and predominantly functions as an accessory protein to DNMT3A [29]. Studies have suggested that DNMT3L may work to localise DNMT3A to chromatin sites in developmental processes and is also seen to interact with DNMT3B in vivo [29].

The methylation of existing genomic CpG islands is carried out by DNMT1 (see Figure 1). Several studies have identified the importance of this enzyme. Dysfunction of DNMT1 has been shown to contribute to various different types of malignancies such as colorectal and prostate cancer [30]. In knockdown mice models, DNMT1 ${ }^{(-/-)}$demonstrated a $90 \%$ loss of methylation and was associated with embryonic lethality suggesting its incompatibility with life [30,31]. Though viable, DNMT1 ${ }^{(-/-)}$embryonic mice stem cells resulted in loss of important cellular function such as differentiation [32]. The loss of DNMT1 and subsequent loss of genomic stability and viability of cellular function [31] are all characteristics noted in many malignant processes.

The methylation of de novo (new) genomic sequence is carried out by both DNMT3A and DNMT3B (see Figure 1) $[29,33]$. The knockdown of both DNMT3b ${ }^{(-/-)}$and DNMT3a ${ }^{(-/-)}$mice embryonic stem cells are not observed to be compatible with life due to the extensive disruption of normal developmental process [33], confirming a crucial role of DNMT3 enzymes in embryonic development.

1.4. TET Enzymes. While the addition of methyl group is carried out by DNMT enzymes, the removal of the methyl group and conversion to unmodified state occur through both the inhibition of DNMT enzymes and also by the action of a group of enzymes known as Ten-Eleven-Translocases (TET 1,2 , and 3). TET enzymes demethylate DNA by producing several intermediates, 5-hydroxymethylcytosine (5hmC), 5formylcytosine (5fC), and 5-carboxylcytosine (5CaC) [34]. In addition to being an intermediate, $5 \mathrm{hmC}$ in particular may have other roles in development, as studies have observed the acquisition of $5 \mathrm{hmC}$ by genes that are activated in neuronal cells during both postnatal developments and also during aging [35].

Mutations in TET enzymes can also contribute to the development of cancer including leukaemia [36]. While TET1 has previously been identified as a fusion protein in MLL (mixed lineage leukaemia) [37], nearly $8-23 \%$ of adult AML patients carry a mutation in TET2 [38-40]. In intermediaterisk cytogenetic AML, TET2 mutations have been associated with poor prognosis [41]. Mutations in TET2 may be an 


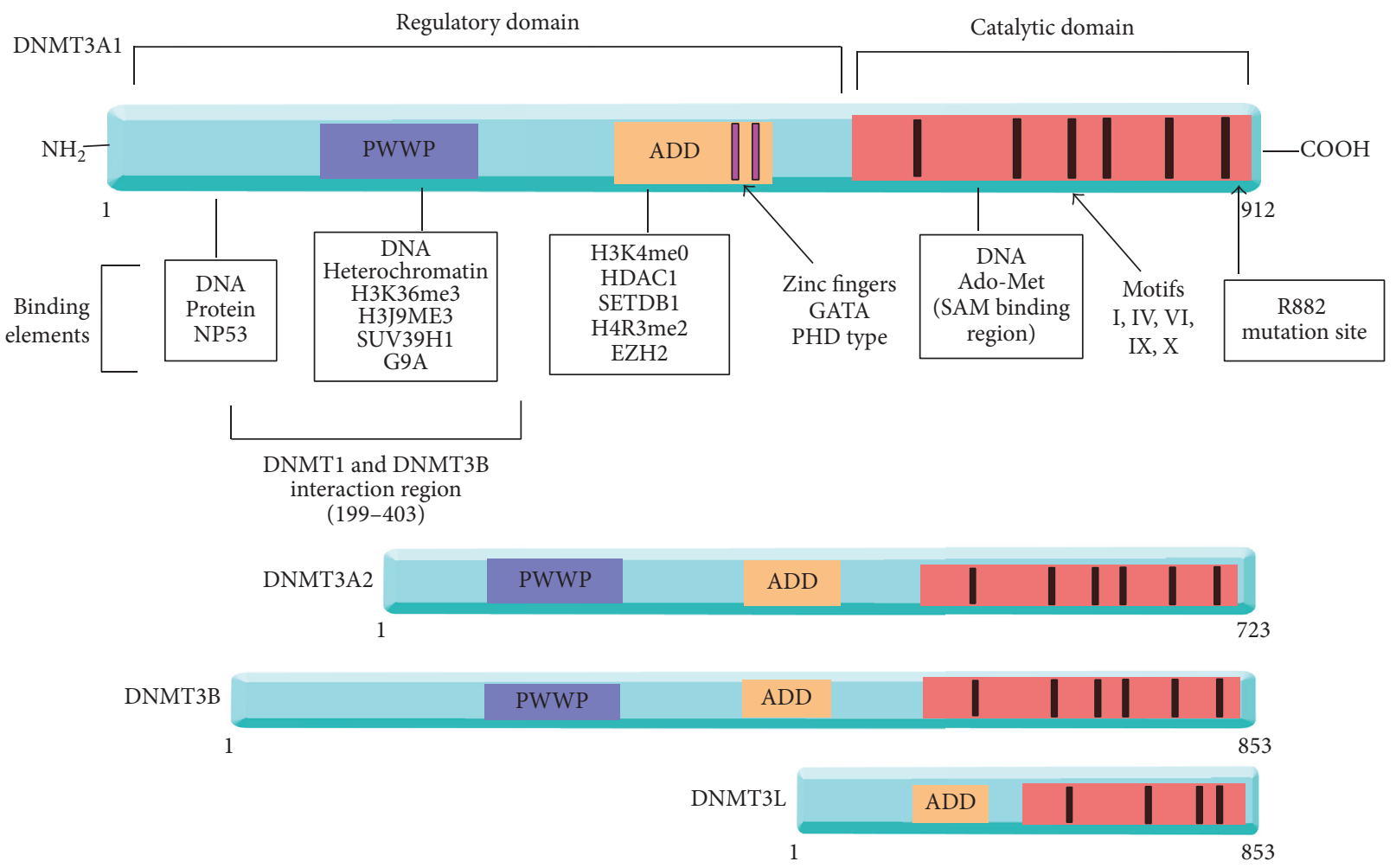

FIgure 2: Structure of DNMT3A splice isoforms, DNMT3B, and DNMT3L. Shown here is the structure of the DNMT3 enzymes. The ADD domain is related to the PHD- (plant homeodomain-) like regulator ATRX and has strong interactions with histones, which is thought to enhance its methylation activity. Meanwhile PWWP domain (Pro-Trp-Trp-Pro) is found to interact with DNA and heterochromatin to help carry out its function, among other proteins. The catalytic domain of the enzyme has motifs conserved across the isoforms. Motifs I are cofactor binding while motifs VIII and IX are for DNA binding and methylation activity at motifs IV, VI, and VIII. The main difference between the two splice isoforms of DNMT3A1 and DNMT3A2 is the extra DNA binding domain located at the amino terminal of DNMT3A1. Other DNMT enzymes are also able to interact with DNMT3A. One common mutation site shown here is R882 residue. This is a hotspot for mutations in haematological malignancy and preleukaemic conditions. Not depicted here are the splice isoforms for DNMT3B and the structure of DNMT1. Adapted from Yang et al. [2].

early phenomenon as they are found in approximately $20 \%$ of preleukaemic conditions such as MDS (myelodysplastic syndrome) and MPN (myeloproliferative neoplasms) [42, 43].

Direct dysfunction in enzymatic activity due to mutation in TET2 and subsequent low levels of $5 \mathrm{hmC}$ have been associated with myeloid tumorigenesis [44]. However, Figueroa et al. $[45,46]$ have suggested that it is the concomitant gain of function IDH1/2 (isocitrate dehydrogenase 1 and 2) mutations which impairs TET2 catalytic activity resulting in tumorigenesis and TET2 mutations alone do not substantially alter $5 \mathrm{hmC}$ levels. In addition to this both murine and human studies have shown that the loss of TET2 does not result in leukaemic transformation but does lead to preleukaemic states such as MDS through activation of downstream genes associated with self-renewal and cellular growth [47]. However, mouse models in contrast to this have shown that the loss of TET2 is sufficient for HSC self-renewal and malignant transformation, proposing that TET2 may still play a part in the leukaemogenic process [48].
1.5. DNMT3A Structure and Function. The DNMT3A protein is encoded on human chromosome $2 \mathrm{p} 23$ and is a small protein of $130 \mathrm{kD}$ with several different domains [49]. Figure 2 shows the structure of DNMT3A; the human enzyme has two known splice isoforms DNMT3A1 and DNMT3A2 [50]. Expression of the two splice isoforms varies in different tissues. DNMT3A2, the shorter of the two isoforms, is predominantly expressed in embryonic stem cell found in the ovaries and testes [50], while DNMT3A1 is expressed ubiquitously in all tissues at low levels [50]. As observed with DNMT3B, transcription of DNMT3A1 occurs at two distinct promoter regions, both of which have differing levels of $\mathrm{CpG}$ content [51]. The control of expression of tissue specific splice forms of DNMT3A and the significance of the two promotor sites remain unclear.

As Figure 2 shows DNMT3A does not work in isolation and is seen to interact with several epigenetic modifiers through its different domains to carry out its function. Though it is unclear how DNMT3A is initially recruited to the chromatin, it is able to interact with the various types 
of histones at these sites [52]. The ADD (ATRX/DNMT3DNMT3L) domain of DNMT3A may interact with histone tails to guide the enzyme to the chromatin [53]. However, interactions between histones and DNMT3A may be more complex than this. Recent data has suggested that the ADD domain may autoinhibit its own catalytic activity and through interaction with histones such as $\mathrm{H} 3 \mathrm{~K} 4 \mathrm{me} 0$ (unmodified histone) this inhibition is released (Guo et al., 2015). Histones such as H3K27me3 are also observed to cover hypomethylated CpG canyons found in HSCs and are suggested to mark gene for methylation [24]. Such canyon regions may potentiate the interaction between DNMT3A and histones for functional purposes as previously discussed with respect to PRC2 gene silencing. However, as canyons are seen to be hypomethylated it is unclear how this interaction encompasses DNMT3A directly.

Several other epigenetic modifiers also bind DNMT3A for functional purposes to modify gene expression. One example of this is histone modifiers, such as H3K9 methyltransferase enzyme, which are observed to interact with DNMT3A [52], though the significance in respect to methylation activity is not well understood. Interactions between DNMT3A and SUV39H1 (histone methyltransferase) have also resulted in $\mathrm{H} 3 \mathrm{~K} 9$ methylation and subsequently reduced gene expression [54]. Another histone modifier that binds to DNMT3A through the ADD domain is EZH2 (Enhancer of Zeste homology 2) (see Figure 2). A catalytic component of $\mathrm{PRC} 2, \mathrm{EZH} 2$ is required for DNMT3A to bind genes that are consequently repressed by EZH2 [55]. Together these two epigenetic regulators may have a role in normal haematopoiesis, as mutations in EZH2 are seen in both MDS and myeloid malignancies [56].

Other members of DNMT family also interact with DNMT3A (see Figure 2). Methylated regions are seen to overlap for DNMT3A and DNMT3B, though it is uncertain why both enzymes are required for methylation of the same site. Some models have suggested that DNMT3A and DNMT3B work as a dimer to methylate certain satellite repeats [57]. The significance of this dimer structure is unclear; whether the dimer is required to localise satellite repeats or potentiate the DNMT3A methylating function still remains to be determined. Certain tissues which lack the accessory protein DNMT3L express both DNMT3A and DNMT3B [57], suggesting that DNMT3B may have an accessory role. When DNMT3L is coexpressed with DNMT3A, enzymatic activity is increased nearly threefold [58] but the mechanism of this is not clearly characterised. DNMTL is not seen to enhance DNMT3A binding to DNA [58] and neither does it appear to help guide DNMT3A to unmodified chromatin [53]. Further studies may identify the significance and relevance of this interaction in human tissue.

\section{DNMT3A and Acute Myeloid Leukaemia}

2.1. Acute Myeloid Leukaemia. AML is haematological cancer that affects the myeloid lineage and causes clonal malignant proliferation of white blood cells [68]. Inhibited differentiation and uncontrolled proliferation lead to accumulation of immature blood cells in the bone marrow; progression of this leads to cytopenia, neutropenia, and thrombocytopenia. Clinical manifestations of symptoms include fatigue, dyspnoea, susceptibility to infections, and haemorrhage. AML occurs predominantly in older adults, with more than half the cases reported in patients older than 65 years. Though rare, infrequent cases of AML in children have been reported [68]. Prognosis for AML patients is partly dependent on the age of patients; younger patients are reported to have overall better 5 -year survival rate than older patients $[68,69]$. Meanwhile the 5-year survival rate for those aged 65 or older is around 15-20\% [68], suggesting that the mutations driving AML in older patients have greater associated lethality than those found in younger patients. Importantly this also demonstrates the devastating nature of AML as a disease.

AML is a disease of genetic heterogeneity as no single mutation is seen to drive AML yet several mutations have been identified to contribute to leukaemogenesis. Cytogenetic or chromosomal abnormalities, such as translocations, are reported in 55\% of patients with AML [70]. Different cytogenetic aberrations can infer differing levels of risk and prognosis as is seen in Table $1[59,70]$. However, cytogenetic abnormalities and molecular mutations can coincide in leukaemia patients [59]. While $40-50 \%$ of AML patients have a normal karyotype and are cytogenetically normal (CNAML), these patients carry various molecular mutations that contribute to AML pathogenesis and as such are characterized as being intermediate-risk group [59].

The progression from single mutations in several different genes to leukaemia is a multistep process. Early simplified models for leukaemogenesis included the two-hit hypothesis, whereby two hits in two different mutation groups were needed [71]. These groups were referred to as Class I and Class II. Mutations in genes that cause uncontrolled proliferation of cells and avoidance of apoptosis were grouped as Class I mutations, while Class II mutations inhibited differentiation as seen in Figure 3.

With respect to AML this theory was supported by genomic sequencing data showing the presence of Classes I and II mutations such as FLT3 (tyrosine kinase) and NPM1 (nucleophosmin) in CN-AML patients with no other identifiable chromosomal abnormalities [72]. In addition to this, Higuchi et al. (2002) demonstrated in leukaemia mice models that a single mutation in genes did not progress to leukaemogenesis, and further mutations from other classes were required [73]. This evidence, in conjunction with the observation that no single mutation has been identified to drive AML, supported the suggestion that more than one mutation is required. Single mutations from Class II are, however, observed to cause preleukaemic conditions such as MDS [74].

However, the two-hit hypothesis is simplistic in regard to mutational groups considered. The role of mutations in epigenetic modifiers such as DNMT3A is excluded from this theory, though data is increasingly proposing that these mutations have a significant contribution to leukaemogenesis. The introduction of mutations from neither Class I nor Class II has added further complexity to understanding haematological malignancies [27]. Figure 3 shows some of these genes from different classes identified to date. 
TABLE 1: Showing the cytogenetic abnormalities that are found in AML and the current known functional consequences of these fusion proteins. Taken and adapted from Kumar et al. (2010) and individual sources as referenced below.

\begin{tabular}{|c|c|c|c|}
\hline Translocations & Oncofusion protein & Frequency in AML & Consequence of translocation \\
\hline $\mathrm{t}(8 ; 21)$ & AML1-ETO & $10 \%$ & $\begin{array}{l}\text { Translocation involves the AML1 (RUNX1), a DNA binding TF important } \\
\text { for haematopoietic differentiation and the ETO gene (a transcriptional } \\
\text { repressor) to give oncofusion protein. The suggested function of the } \\
\text { oncofusion is to exert dominant-negative effect on AML1 }{ }^{\text {WT }} \text { to suppress } \\
\text { haematopoietic differentiation [59]. }\end{array}$ \\
\hline $\mathrm{t}(15 ; 17)$ & PML-RAR $\alpha$ & $10 \%$ & $\begin{array}{l}\text { The PML-RAR } \alpha \text { is expressed in haematopoietic myeloid cells and functions } \\
\text { as a transcriptional repressor of genes involved in apoptosis, differentiation, } \\
\text { and self-renewal [59]. }\end{array}$ \\
\hline $\operatorname{inv}(16)$ & CBF $\beta-$ MYH11 & $5-8 \%$ & $\begin{array}{l}\mathrm{CBF} \beta-\mathrm{MYH} 11 \text { oncofusion protein is suggested to interact with AML1 to } \\
\text { repress transcription in myeloid cells [59]. }\end{array}$ \\
\hline $\operatorname{der}(11 \mathrm{q} 23)$ & MLL-fusions & $4 \%$ & $\begin{array}{l}\text { Observed in various acute leukaemia and is associated with poor } \\
\text { prognosis. The oncofusion protein acts a potent oncogene. It directs the } \\
\text { MLL oncoprotein targets complex to DNA sites, while fusion part works as } \\
\text { an effector unit [59]. }\end{array}$ \\
\hline $\mathrm{t}(9 ; 22)$ & BCR-ABL1 & $2 \%$ & Rare Philadelphia-positive AML [60]. \\
\hline $\mathrm{t}(6 ; 9)$ & DEK-CAN & $<1 \%$ & $\begin{array}{l}\text { Chimeric fusion protein encodes a mRNA involved in leukaemogenesis } \\
\text { [61]. }\end{array}$ \\
\hline $\mathrm{t}(1 ; 22)$ & OTT-MAL & $<1 \%$ & $\begin{array}{l}\text { May regulate chromatin structure, HOX differentiation pathways, or } \\
\text { extracellular signaling [62]. }\end{array}$ \\
\hline $\mathrm{t}(8 ; 16)$ & MOZ-CBP & $<1 \%$ & $\begin{array}{l}\text { Upregulation of HOX genes and downregulation of WT1; shares similar } \\
\text { pathway as MLL [63]. }\end{array}$ \\
\hline $\mathrm{t}(7 ; 11)$ & NUP98-HOXA9 & $<1 \%$ & Inhibition of HOXA9 effecting terminal differentiation [64]. \\
\hline $\operatorname{inv}(3)$ & RPN1-EVI1 & $<1 \%$ & $\begin{array}{l}\text { The EVI1 fusion induces gene transcription and promotes leukaemogenesis } \\
\text { [65]. }\end{array}$ \\
\hline $\mathrm{t}(16 ; 21)$ & FUS-ERG & $<1 \%$ & $\begin{array}{l}\text { Oncofusion protein that acts as a transcriptional repressor of } \\
\text { haematopoietic specific genes [66]. }\end{array}$ \\
\hline
\end{tabular}

2.2. Epigenetic Mutations and AML. The use of more advanced whole genome and whole exome of sequencing techniques has allowed for the identification of several mutations in epigenetic regulators (see Figure 3) in AML patients. Further research into these epigenetic modifiers has enhanced our understanding of not only the function of these modifiers in normal developmental and cellular process but also the consequences of aberrant proteins in diseases such as AML. Up to $70 \%$ of de novo AML patients carry a single mutation in epigenetic modifiers such as DNMT3A and TET 2 and in some cases more than one mutation in more than one epigenetic regulator [75]. Such mutations have been noted in myeloid malignancies and preleukaemic states but also in some lymphoid malignancies, notably Tcell angioimmunoblastic lymphoma [76]. Extensive research into these epigenetic modifiers has given insight into their mechanisms of action in AML and here we will focus on the current research surrounding DNMT3A mutations in AML and the theories surrounding their mechanism of action.

2.3. AML, DNMT3A Mutations, and DNA Methylation Patterns. Aberrant DNA methylation patterns have been observed in several studies investigating AML pathogenesis. Though global hypomethylation has been seen in various genes associated with the cellular replication, hypermethylation is also observed in specific $\mathrm{CpG}$ promoter regions associated with tumor repressor genes involved with differentiation and apoptosis [45, 67, 77]. In addition to this specific signature patterns of methylation have been observed across cytogenetically abnormal AML [77]. One example is observed in PML-RAR $\alpha-\mathrm{t}(15 ; 17)$ AML, where distinct hypomethylation and hypermethylation of gene are seen, while $t(8 ; 21)$ subtype AML predominant hypomethylation is observed [67]. A summary of the alterations in methylation pattern, compiled by Schoofs et al. (2014), can be seen in Table 2 [67]. It is clear from the findings shown in Table 2 that much remains unclear about the aberrant methylation patterns in relation to AML and specific mutations.

Several studies have attempted to identify the association between specific methylation patterns, prognosis, and clinical outcomes [46, 78]. Figueroa et al. [45, 46] identified that AML patients highly expressing $t(8 ; 21)$, inv(16), and $t(15 ; 17)$ had distinct methylation patterns and therefore such groups could be clustered together to predict clinical outcomes [45]. Additionally, Hájková et al. (2012) who investigated 79 AML patients and also found that high- or intermediate-risk AML patients with higher DNA methylation were seen to have better clinical outcomes [78]. In contrast to this, lower levels of methylation were associated with higher relapse and lower overall survival for AML patients [78]. Though there is some evidence that subtypes of AML have distinct aberrant methylation patterns this does, however, present the difficulty of targeting such patterns with universal epigenetic changes. 


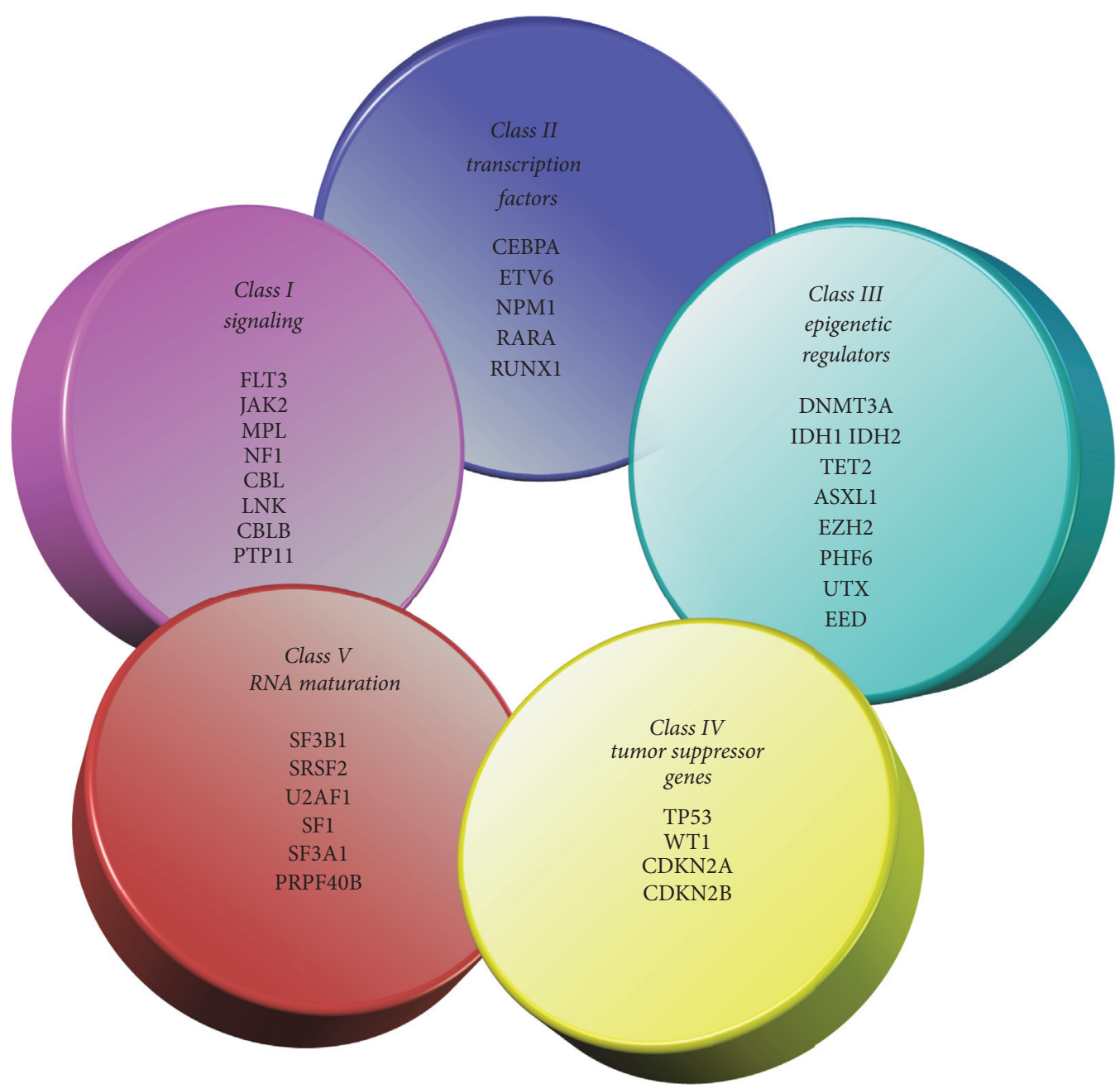

FIGURE 3: Some of the key classes of genes that are observed to contribute to the development of malignancy. All are potential targets for therapy in leukaemia. Adapted from Murati et al. [27].

One frequently mutated epigenetic regulator in AML is DNMT3A, with approximately $22 \%$ of CN-AML patients carrying a DNMT3A mutation [79]. Though this may suggest a significant role for DNMT3A mutations in leukaemogenesis, the downstream consequence of the identified mutations in the enzyme remains largely underdetermined. While single mutations in DNMT3A do not evolve into leukaemia or alter levels of methylation, complete knockdown of DNMT3A in murine models is seen to produce cellular properties such as inhibited differentiation [80]. Challen and colleagues (2012) have suggested this was primarily due to interruptions in downstream regulators of DNMT3A such as RUNX1 (Runtrelated transcription factor 1), which produce malignant properties observed with DNMT3A knockdown [80].

While it may be proposed that DNMT3A mutations contribute to altered methylation patterns in AML, how this occurs is not well characterized. Aberrant hypomethylation patterns have been noted to occur regularly in AML, specifically in non-CpG islands region, while hypermethylation of promotor $\mathrm{CpG}$ islands has been highly associated with mutated DNMT3A [81]. However, there is conflicting evidence regarding global methylation signatures observed in AML. Some studies have suggested no decrease in global hypomethylation [82], while other groups have identified the association of global hypomethylation patterns in respect to DNMT3A mutation, particularly affecting HOX (homeobox domain containing transcription factors) gene expression $[24,78,81,83]$. HOX genes are a family of conserved homeodomain-containing transcription factors involved in developmental processes and are seen to have an important role in normal haematopoiesis $[84,85]$. Though HOXA5, HOXA9, and PAX appear to be overexpressed due to hypomethylation in AML [81], the significance of these genes in AML remains to be determined. The overexpression of HOXA5 and HOXC4 genes, however, can ultimately affect differentiation state of myeloid cells and HSCs proliferation [81]. Further methylation studies are required to understand the impact of DNMT3A mutations on direct modulation of such genes.

While several studies have identified hypermethylation of CpG island promotor in AML [86, 87], less is known about nonpromotor sites methylation. In whole-genome studies investigating methylation patterns, predominantly 
TABLE 2: Effect of mutation on aberrant methylation (taken from [67]). It is clear from this table that many of the downstream consequences in relation to development of AML are still unclear. Many of these cytogenetic mutations causing AML are rare and have only been observed in a few patients to date.

\begin{tabular}{|c|c|c|}
\hline $\begin{array}{l}\text { Genetic } \\
\text { alteration }\end{array}$ & Signature of DNA methylation patterns & $\begin{array}{l}\text { Suggested mechanism of aberrant DNA methylation } \\
\text { induction in AML }\end{array}$ \\
\hline $\begin{array}{l}\text { PML-RARa } \\
\mathrm{t}(15 ; 17)\end{array}$ & Accentuated hypermethylation and hypomethylation. & $\begin{array}{l}\text { PML-RARa suggested to recruit DNMTs to binding site } \\
\text { causing DNA hypermethylation. Secondary epigenetic } \\
\text { dysregulation as PML-RARa binds to genomic regions } \\
\text { of epigenetic modifiers including DNMT3A. }\end{array}$ \\
\hline $\begin{array}{l}\text { AML1/ETO } \\
\mathrm{t}(8 ; 21)\end{array}$ & $\begin{array}{l}\text { Accentuated hypermethylation and hypomethylation. } \\
\text { Though predominantly hypomethylation. }\end{array}$ & $\begin{array}{l}\text { Unclear mechanism } \\
\text { AML1/ETO may recruit DNMT1 and HDAC1. Possibly } \\
\text { works through secondary DNA methylation disruption } \\
\text { of AML1-ETO target genes. }\end{array}$ \\
\hline $\begin{array}{l}\text { CBFb-MYH11 } \\
\text { inv(16)- } \\
t(16 ; 16)\end{array}$ & Predominantly hypomethylation. & Unclear mechanism. \\
\hline TET2 mutations & Hypermethylation signature. & $\begin{array}{l}\text { Mutated TET2 is impaired in its hydroxymethylation } \\
\text { capacity. Unclear if DNA hypermethylated genes are } \\
\text { direct TET2 target genes. }\end{array}$ \\
\hline $\begin{array}{l}\text { IDH } 1 / 2 \\
\text { mutations }\end{array}$ & Pronounced genome wide hypermethylation signature. & $\begin{array}{l}\text { Possibly via IDH (isocitrate dehydrogenase) mutations } \\
\text { result in DNA hypermethylation via inhibition of } \\
\alpha \text {-ketoglutarate dependent dioxygenases (e.g., TET2). }\end{array}$ \\
\hline $\begin{array}{l}\text { DNMT3A } \\
\text { mutations }\end{array}$ & $\begin{array}{l}\text { Genome-wide DNA hypomethylation signature: studies } \\
\text { give mixed findings. }\end{array}$ & $\begin{array}{l}\text { Mechanism of aberrant DNA methylation induction } \\
\text { unclear. In vitro mechanism may be through loss of } \\
\text { catalytic activity via R } 882 \mathrm{H} \text { mutation. Unclear in vivo } \\
\text { mechanism. }\end{array}$ \\
\hline $\begin{array}{l}\text { MLL- } \\
\text { translocation } \\
-(11 \mathrm{q} 23)\end{array}$ & Pronounced DNA hypomethylation signature. & Unclear mechanism. \\
\hline $\begin{array}{l}\operatorname{CEBP} \alpha \\
\text { mutations }\end{array}$ & $\begin{array}{l}\text { Two patterns of hypomethylated and hypermethylated } \\
\text { sites depending on the detection method used. }\end{array}$ & Unclear mechanism. \\
\hline $\begin{array}{l}\text { RUNX1 } \\
\text { mutations }\end{array}$ & $\begin{array}{l}\text { Discrete hypermethylation and hypomethylation } \\
\text { signature. }\end{array}$ & Unclear mechanism. \\
\hline $\begin{array}{l}\text { NPM1 } \\
\text { mutations }\end{array}$ & $\begin{array}{l}\text { Mixed hypermethylation and hypomethylation pattern. } \\
\text { Strong hypomethylation in some studies. }\end{array}$ & Unclear mechanism. \\
\hline
\end{tabular}

hypomethylation was observed in Dnmt3a $\mathrm{a}^{(-/-)}$HSCs [24]. This was supported by sequential transplants of nullDNMT3A in murine models also producing global hypomethylation in progeny of null cells [80]. Specifically, loss of methylation was observed in intergenic sites in murine Dnmt3a(-/-) HSCs [88], supporting the observations in distant $\mathrm{CpG}$ shelves/shores and a small number of loci, in other studies [79, 81]. But what remains undetermined is the overall influence such alterations in methylation patterns have in leukaemogenesis.

2.4. The R882 Codon Mutation in DNMT3A. Parallel DNA sequencing techniques have identified that one of the most commonly mutated sites in DNMT3A in AML patients is the R882 hotspot $[79,83]$. Approximately $60 \%$ of the mutations found in DNMT3A in AML are found to occur at this residue in the DNMT3A catalytic domain [79]. As this mutation is highly associated with poor prognosis in adults with AML [89], several studies have aimed to understand the mechanism and consequences of the R882 mutation.
However, this mutation is not exclusive to just AML. Though less frequently observed, it is nevertheless present in several other myeloid malignancies and proliferative disorders such as MDS [90]. As observed with AML, MDS patients with R882 mutations are seen to have a significantly worse overall prognosis and a more rapid progression to leukaemia than those patients with non-R882 DNMT3A mutations [90]. In addition to this observation, the recent identification of other preleukaemic clones in individuals over the age of 70 has led to the theory that the R882 mutation is one that occurs early in the leukaemogenesis [91, 92].

Of the most common single codon mutation at the R882 residue is the arginine $(\mathrm{R})$ to histidine $(\mathrm{H})$ missense mutation $[79,83]$. Holz-Schietinger and colleagues (2012) suggested that the $\mathrm{R} 882 \mathrm{H}$ mutation formed a hypomorphic protein, whereby the DNMT3A ${ }^{\text {MUT }}$ produces a dominant-negative effect on the enzymatic activity of DNMT3A ${ }^{\text {WT }}$ [93]. Work by Kim et al. (2013) has supported this by showing that the coexpression in vitro of both DNMT3A ${ }^{\text {WT }}$ and DNMT3 ${ }^{\text {MUT }}$ in heterogeneous cells produces either a gain of function 
action or a dominant-negative effect [94]. Around 20\% of remaining function of DNMT3 $\mathrm{A}^{\mathrm{WT}}$ is still maintained in the presence of $\mathrm{R} 882 \mathrm{H}$ mutations, potentially due to formation of functioning DNMT3A ${ }^{\text {WT }}$ dimers [93]. Disrupted dimerization by DNMT3A ${ }^{\text {MUT }}$ is observed to suppress half the DNMT3 ${ }^{\text {WT }}$ activity to produce approximately 2.5 -fold reduction in methylation activity [93]. This suppression of normal activity and subsequent altered methylation could be one possible mechanism of leukaemogenesis. While the hypomethylation observed in murine models carrying the $\mathrm{R} 882 \mathrm{H}$ mutation was initially thought to produce loss-offunction function, the successful use of the hypomethylating agent decitabine in R882 patients contraindicates this theory [95]. Rather than the R882H mutations causing increased levels of global hypomethylation, an argument could be made for the mutation alternatively causing altered patterns in methylation contributing to leukaemogenesis.

Recent data by Russler-Germain and colleagues (2014) have further demonstrated a possible in vitro mechanism of action for $\mathrm{R} 882 \mathrm{H}$ mutation. In contradiction to previous studies, they suggested that coexpression of both DNMT3A $^{\text {MUT }}$ and DNMT3A ${ }^{\text {WT }}$ is required to produce the dominant-negative effect [96]. Furthermore, rather than the dimerisation as suggested by Holz-Schietinger et al. [93], tetramers of DNMT3A ${ }^{\text {WT }}$ are seen to form $[93,96]$. It is the loss of formation of these tetramers through the binding of DNMT3A $^{\text {WT }}$ to DNMT3A ${ }^{\text {MUT }}$ in a dominant-negative fashion that is thought to be pathogenic as it produces inactive intracellular complexes [96]. Interestingly, the authors also showed that this also subsequently produced a small but significant decrease in CpG methylation [96]. While global hypomethylation of $\mathrm{CpG}$ islands and shores has been shown in other studies to be associated with the $\mathrm{R} 882 \mathrm{H}$ mutation $[81,96]$, hypermethylation of $\mathrm{CpG}$ promoter regions has also been associated with the same mutation in AML $[81,83]$. This gives viability to the theory that, rather than global reduction in methylation patterns, altered patterns are observed in relation to $\mathrm{R} 882 \mathrm{H}$ mutations and the extent of severity of the mutated enzyme is ultimately dependent on the individual cellular levels of DNMT3A ${ }^{\text {MUT }}$ present.

Much still remains unclear regarding the $\mathrm{R} 882 \mathrm{H}$ mutation in respect to its activity and how this mutation works in conjunction with other DNMT3A mutations that are commonly observed, as is the case with many patients who accumulate several mutations over their lifetime. Translating such findings across to AML patients is difficult, as isolating the function of single mutations in patient cells which have multitude of mutations can be challenging in terms of determining functionality. Further research would endeavour to understand the dominant-negative effect in AML patient cells. This may also provide future therapeutic solutions that would be beneficial to AML patients with this commonly mutated residue. If heterozygous patients have some level of functioning DNMT3 $\mathrm{A}^{\mathrm{WT}}$ present, exploiting this action through targeted inhibition of the R882 DNMT3A ${ }^{\text {MUT }}$ could be one avenue to pursue. However, the difficulty presented with such therapy would be the selective targeting of mutant DNMT3A over wildtype DNMT3A.

\section{Clonal Haematopoiesis of Indeterminate Potential and DNMT3A}

A crucial step in the development of premalignant and haematological malignancy is the clonal expansion of HSC carrying somatic mutations. Mutated epigenetic regulators such as DNMT3A are found in these clones of HSC and such mutations are seen to facilitate early clonal expansion in preleukemic conditions [90, 97].

While mutations in epigenetic regulators have been observed in AML and preleukaemic conditions such as MDS, recent data has shown the existence of such mutations in elderly individuals in a novel preleukemic condition referred to as clonal haematopoiesis of indeterminate potential. Increasingly referred to as CHIP, this novel preleukemic condition is seen to differ diagnostically from other preleukemic conditions such as monoclonal gammopathy of unknown significance (MGUS) and monoclonal B-cell lymphocytosis (MBL) $[28,98]$. The defining features of CHIP are illustrated in Figure 4. Large studies using whole-exome sequencing techniques have recently identified this phenomenon, specifically characterizing the presence of somatic mutations in three key epigenetic regulators: TET2, ASXL1, and importantly DNMT3A [91, 92]. It was concluded by both Genovese et al. (2015) and Jaiswal et al. (2014) that somatic mutations in these clones inferred an increased risk of haematological malignancy [91, 92]. Of these elderly individuals who carried mutations in DNMT3A and other epigenetic modifiers, only $4 \%$ developed lymphoid or myeloid malignancy. Though these clones carried varied DNMT3A mutations, progression to AML with DNMT3A was not observed in all cases. This is the defining criterion for CHIP, whereby the clones in CHIP carry mutations in genes notably prominent in the development of haematological neoplasms; however, the malignancy itself is absent [28].

While the mutations found in AML in DNMT3A, as previously discussed, regularly occur at the R882 region of the protein, the presence of such mutations in CHIP is undetermined. If absent or infrequent in the landscape of DNMT3A mutations identified in CHIP, it could suggest a possible theory regarding the lack of progression to myeloid malignancy. If, however, such mutations are present, this could further support the notion of R882 mutation being a founder mutation, one which is acquired in early leukaemogenesis and leads to clonal expansion.

\section{Conclusion}

The role of the epigenetic modifier DNMT3A in haematological cancers is becoming increasingly more important. The presence of key mutations in preleukemic stem cells in MDS and AML, in addition to CHIP, further supports the theory that such mutations in DNMT3A could be "founder" mutations, especially in the case of mutations found at the R882 codon hotspot. These mutations appear to arise in HSCs and play a key role in the initiation of haematological malignancy. The occurrence of such mutations has been shown to increase with age and result in clonal expansion of mutated cells. The significance of such mutations in CHIP 


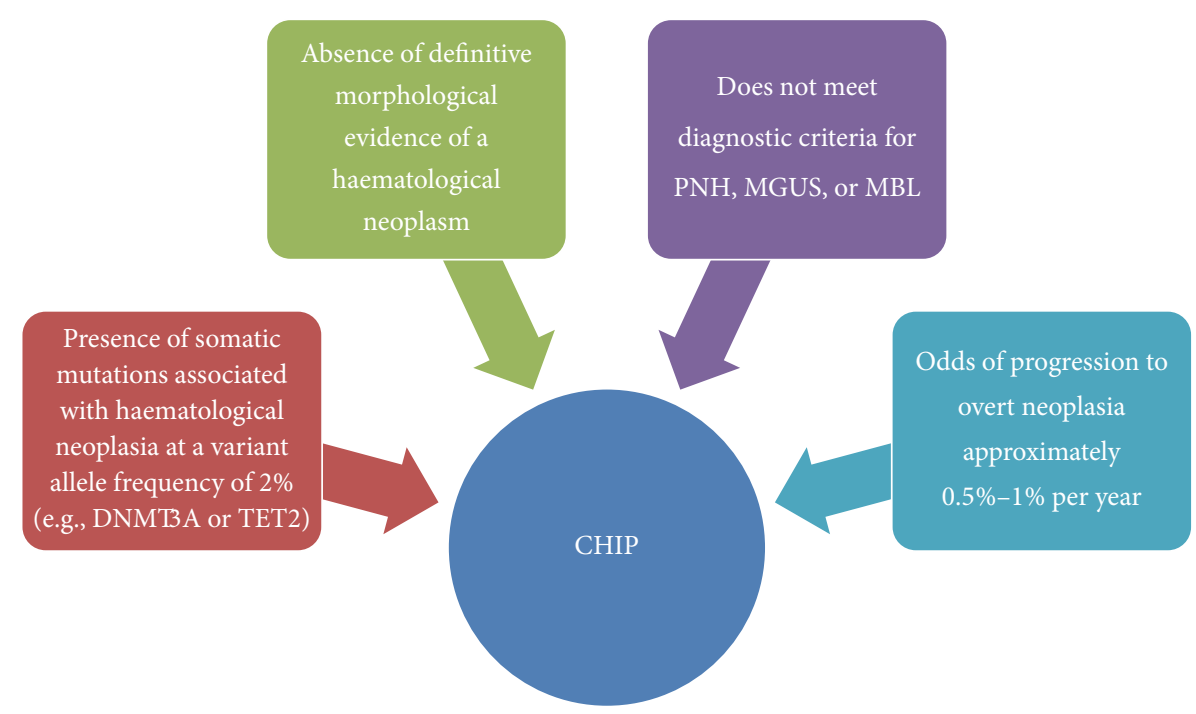

Figure 4: Criteria for clonal haematopoiesis of indeterminate potential. Adapted from Steensma et al. [28]. Paroxysmal nocturnal haemoglobinuria (PNH), monoclonal gammopathy of unknown significance (MGUS), and monoclonal B-cell lymphocytosis (MBL).

is still unclear but the relationship between CHIP and age may suggest that such mutations are a method of adaption to the aging bone marrow environment, potentially allowing enhanced HSC self-renewal in older individuals.

What is clear from this review is that while mutations in DNMT3A play a significant role in the development of haematological disorders such as AML and MDS, understanding of the mechanisms and downstream consequences of such mutations is still undetermined. Further studies may enlighten us to the role of DNMT3A in AML and CHIP, facilitating possible therapeutic targeting in the future.

\section{Competing Interests}

The authors declare that there is no conflict of interests.

\section{References}

[1] A. Bird, "DNA methylation patterns and epigenetic memory," Genes and Development, vol. 16, no. 1, pp. 6-21, 2002.

[2] L. Yang, R. Rau, and M. A. Goodell, "DNMT3A in haematological malignancies," Nature Reviews Cancer, vol. 15, no. 3, pp. 152-165, 2015.

[3] R. Holliday and G. W. Grigg, "DNA methylation and mutation," Mutation Research, vol. 285, no. 1, pp. 61-67, 1993.

[4] M. M. Suzuki and A. Bird, "DNA methylation landscapes: provocative insights from epigenomics," Nature Reviews Genetics, vol. 9, no. 6, pp. 465-476, 2008.

[5] M. Weber, I. Hellmann, M. B. Stadler et al., "Distribution, silencing potential and evolutionary impact of promoter DNA methylation in the human genome," Nature Genetics, vol. 39, no. 4, pp. 457-466, 2007.

[6] A. M. Deaton and A. Bird, "CpG islands and the regulation of transcription," Genes and Development, vol. 25, no. 10, pp. 10101022, 2011.
[7] A. Meissner, T. S. Mikkelsen, H. Gu et al., "Genome-scale DNA methylation maps of pluripotent and differentiated cells," Nature, vol. 454, no. 7205, pp. 766-770, 2008.

[8] Y. Oki and J.-P. J. Issa, "Epigenetic mechanisms in AML-a target for therapy," in Acute Myelogenous Leukemia, vol. 145 of Cancer Treatment and Research, pp. 19-40, Springer, New York, NY, USA, 2010.

[9] E. L. Putiri and K. D. Robertson, "Epigenetic mechanisms and genome stability," Clinical Epigenetics, vol. 2, no. 2, pp. 299-314, 2011.

[10] J. P. Reddington, S. Pennings, and R. R. Meehan, "Noncanonical functions of the DNA methylome in gene regulation," Biochemical Journal, vol. 451, no. 1, pp. 13-23, 2013.

[11] M. D. Lynch, A. J. H. Smith, M. De Gobbi et al., "An interspecies analysis reveals a key role for unmethylated $\mathrm{CpG}$ dinucleotides in vertebrate Polycomb complex recruitment," EMBO Journal, vol. 31, no. 2, pp. 317-329, 2012.

[12] E. M. Mendenhall, R. P. Koche, T. Truong et al., "GC-rich sequence elements recruit PRC2 in mammalian ES cells," PLoS genetics, vol. 6, no. 12, p. e1001244, 2010.

[13] M. Ku, R. P. Koche, E. Rheinbay et al., "Genomewide analysis of PRC1 and PRC2 occupancy identifies two classes of bivalent domains," PLoS Genetics, vol. 4, no. 10, Article ID e1000242, 2008.

[14] J. P. Reddington, S. M. Perricone, C. E. Nestor et al., "Redistribution of H3K27me3 upon DNA hypomethylation results in derepression of Polycomb target genes," Genome Biology, vol. 14, no. 3, article no. R25, 2013.

[15] A. B. Brinkman, H. Gu, S. J. J. Bartels et al., "Sequential ChIP-bisulfite sequencing enables direct genome-scale investigation of chromatin and DNA methylation cross-talk," Genome Research, vol. 22, no. 6, pp. 1128-1138, 2012.

[16] A. L. Statham, M. D. Robinson, J. Z. Song, M. W. Coolen, C. Stirzaker, and S. J. Clark, "Bisulfite sequencing of chromatin immunoprecipitated DNA (BisChIP-seq) directly informs methylation status of histone-modified DNA," Genome Research, vol. 22, no. 6, pp. 1120-1127, 2012. 
[17] H. Meng, Y. Cao, J. Qin et al., "DNA methylation, its mediators and genome integrity," International Journal of Biological Sciences, vol. 11, no. 5, pp. 604-617, 2015.

[18] J. Borgel, S. Guibert, Y. Li et al., "Targets and dynamics of promoter DNA methylation during early mouse development," Nature Genetics, vol. 42, no. 12, pp. 1093-1100, 2010.

[19] S. Guibert, T. Forné, and M. Weber, "Global profiling of DNA methylation erasure in mouse primordial germ cells," Genome Research, vol. 22, no. 4, pp. 633-641, 2012.

[20] T. H. Bestor, J. R. Edwards, and M. Boulard, "Notes on the role of dynamic DNA methylation in mammalian development," Proceedings of the National Academy of Sciences of the United States of America, vol. 112, no. 22, pp. 6796-6799, 2015.

[21] I.-H. Oh and R. K. Humphries, "Concise review: multidimensional regulation of the hematopoietic stem cell state," Stem Cells, vol. 30, no. 1, pp. 82-88, 2012.

[22] M. Bibikova, B. Barnes, C. Tsan et al., "High density DNA methylation array with single CpG site resolution," Genomics, vol. 98, no. 4, pp. 288-295, 2011.

[23] R. Edgar, P. P. Tan, E. Portales-Casamar, and P. Pavlidis, "Meta-analysis of human methylomes reveals stably methylated sequences surrounding CpG islands associated with high gene expression," Epigenetics \& Chromatin, vol. 7, no. 1, article no. 28, 2014.

[24] M. Jeong, D. Sun, M. Luo et al., "Large conserved domains of low DNA methylation maintained by Dnmt3a," Nature Genetics, vol. 46, no. 1, pp. 17-23, 2014.

[25] M. H. Saied, J. Marzec, S. Khalid et al., "Genome wide analysis of acute myeloid leukemia reveal leukemia specific methylome and subtype specific hypomethylation of repeats," PLOS ONE, vol. 7, no. 3, Article ID e33213, 2012.

[26] A. Blattler, L. Yao, H. Witt et al., "Global loss of DNA methylation uncovers intronic enhancers in genes showing expression changes," Genome Biology, vol. 15, article 469, 2014.

[27] A. Murati, M. Brecqueville, R. Devillier, M.-J. Mozziconacci, V. Gelsi-Boyer, and D. Birnbaum, "Myeloid malignancies: mutations, models and management," BMC Cancer, vol. 12, article no. 304, 2012.

[28] D. P. Steensma, R. Bejar, S. Jaiswal et al., "Clonal hematopoiesis of indeterminate potential and its distinction from myelodysplastic syndromes," Blood, vol. 126, no. 1, pp. 9-16, 2015.

[29] B. L. Wienholz, M. S. Kareta, A. H. Moarefi, C. A. Gordon, P. A. Ginno, and F. Chédin, "DNMT3L modulates significant and distinct flanking sequence preference for DNA methylation by DNMT3A and DNMT3B in vivo," PLOS Genetics, vol. 6, no. 9, Article ID e1001106, 2010.

[30] D. Subramaniam, R. Thombre, A. Dhar, and S. Anant, "DNA methyltransferases: a novel target for prevention and therapy," Frontiers in Oncology, vol. 4, article 80, 2014.

[31] K. D. Brown and K. D. Robertson, "DNMT1 knockout delivers a strong blow to genome stability and cell viability," Nature Genetics, vol. 39, no. 3, pp. 289-290, 2007.

[32] L. Jackson-Grusby, C. Beard, R. Possemato et al., "Loss of genomic methylation causes p53-dependent apoptosis and epigenetic deregulation," Nature Genetics, vol. 27, no. 1, pp. 31-39, 2001.

[33] M. Okano, D. W. Bell, D. A. Haber, and E. Li, "DNA methyltransferases Dnmt3a and Dnmt3b are essential for de novo methylation and mammalian development," Cell, vol. 99, no. 3, pp. 247-257, 1999.
[34] S. Ito, A. C. D’Alessio, O. V. Taranova, K. Hong, L. C. Sowers, and Y. Zhang, "Role of tet proteins in $5 \mathrm{mC}$ to $5 \mathrm{hmC}$ conversion, EScell self-renewal and inner cell mass specification," Nature, vol. 466, no. 7310, pp. 1129-1133, 2010.

[35] K. E. Szulwach, X. Li, Y. Li et al., "5-hmC-mediated epigenetic dynamics during postnatal neurodevelopment and aging," Nature Neuroscience, vol. 14, no. 12, pp. 1607-1616, 2011.

[36] S. R. M. Kinney and S. Pradhan, “Ten eleven translocation enzymes and 5-hydroxymethylation in mammalian development and cancer," Advances in Experimental Medicine and Biology, vol. 754, pp. 57-79, 2013.

[37] H. Huang, X. Jiang, Z. Li et al., "TET1 plays an essential oncogenic role in MLL-rearranged leukemia," Proceedings of the National Academy of Sciences of the United States of America, vol. 110, no. 29, pp. 11994-11999, 2013.

[38] F. Delhommeau, S. Dupont, V. Della Valle et al., "Mutation in TET2 in myeloid cancers," New England Journal of Medicine, vol. 360, no. 22, pp. 2289-2301, 2009.

[39] K. H. Metzeler, K. Maharry, M. D. Radmacher et al., "TET2 mutations improve the new European LeukemiaNet risk classification of acute myeloid leukemia: a cancer and leukemia group B study," Journal of Clinical Oncology, vol. 29, no. 10, pp. 13731381, 2011.

[40] S. Weissmann, T. Alpermann, V. Grossmann et al., "Landscape of TET2 mutations in acute myeloid leukemia," Leukemia, vol. 26, no. 5, pp. 934-942, 2012.

[41] W.-C. Chou, S.-C. Chou, C.-Y. Liu et al., "TET2 mutation is an unfavorable prognostic factor in acute myeloid leukemia patients with intermediate-risk cytogenetics," Blood, vol. 118, no. 14, pp. 3803-3810, 2011.

[42] O. Abdel-Wahab, A. Mullally, C. Hedvat et al., "Genetic characterization of TET1, TET2, and TET3 alterations in myeloid malignancies," Blood, vol. 114, no. 1, pp. 144-147, 2009.

[43] S. M. C. Langemeijer, R. P. Kuiper, M. Berends et al., "Acquired mutations in TET2 are common in myelodysplastic syndromes," Nature Genetics, vol. 41, no. 7, pp. 838-842, 2009.

[44] M. Ko, Y. Huang, A. M. Jankowska et al., "Impaired hydroxylation of 5-methylcytosine in myeloid cancers with mutant TET2," Nature, vol. 468, no. 7325, pp. 839-843, 2010.

[45] M. E. Figueroa, S. Lugthart, Y. Li et al., "DNA methylation signatures identify biologically distinct subtypes in acute myeloid leukemia," Cancer Cell, vol. 17, no. 1, pp. 13-27, 2010.

[46] M. E. Figueroa, O. Abdel-Wahab, C. Lu et al., "Leukemic IDH1 and IDH 2 mutations result in a hypermethylation phenotype, disrupt TET2 function, and impair hematopoietic differentiation," Cancer Cell, vol. 18, no. 6, pp. 553-567, 2010.

[47] L. Scourzic, E. Mouly, and O. A. Bernard, "TET proteins and the control of cytosine demethylation in cancer," Genome Medicine, vol. 7, no. 1, article 9, 2015.

[48] K. Moran-Crusio, L. Reavie, A. Shih et al., "Tet2 loss leads to increased hematopoietic stem cell self-renewal and myeloid transformation," Cancer Cell, vol. 20, no. 1, pp. 11-24, 2011.

[49] K. D. Robertson, E. Uzvolgyi, G. Liang et al., "The human DNA methyltransferases (DNMTs) 1, 3a and 3b: coordinate mRNA expression in normal tissues and overexpression in tumors," Nucleic Acids Research, vol. 27, no. 11, pp. 2291-2298, 1999.

[50] T. Chen, Y. Ueda, S. Xie, and E. Li, "A novel Dnmt3a isoform produced from an alternative promoter localizes to euchromatin and its expression correlates with active de novo methylation," The Journal of Biological Chemistry, vol. 277, no. 41, pp. 38746-38754, 2002. 
[51] Y. Yanagisawa, E. Ito, Y. Yuasa, and K. Maruyama, “The human DNA methyltransferases DNMT3A and DNMT3B have two types of promoters with different $\mathrm{CpG}$ contents," Biochimica et Biophysica Acta (BBA)-Gene Structure and Expression, vol. 1577, no. 3, pp. 457-465, 2002.

[52] H. Cedar and Y. Bergman, "Linking DNA methylation and histone modification: patterns and paradigms," Nature Reviews Genetics, vol. 10, no. 5, pp. 295-304, 2009.

[53] Y. Zhang, R. Jurkowska, S. Soeroes et al., "Chromatin methylation activity of Dnmt3a and Dnmt3a/3L is guided by interaction of the ADD domain with the histone H3 tail," Nucleic Acids Research, vol. 38, no. 13, pp. 4246-4253, 2010.

[54] N. R. Rose and R. J. Klose, "Understanding the relationship between DNA methylation and histone lysine methylation," Biochimica et Biophysica Acta, vol. 1839, no. 12, pp. 1362-1372, 2014.

[55] E. Viré, C. Brenner, R. Deplus et al., "The Polycomb group protein EZH2 directly controls DNA methylation," Nature, vol. 439, pp. 871-874, 2006.

[56] F. Xu and X. Li, "The role of histone methyltransferase EZH2 in myelodysplastic syndromes," Expert Review of Hematology, vol. 5, no. 2, pp. 177-185, 2012.

[57] T. Chen, N. Tsujimoto, and E. Li, "The PWWP domain of Dnmt3a and Dnmt3b is required for directing DNA methylation to the major satellite repeats at pericentric heterochromatin," Molecular and Cellular Biology, vol. 24, no. 20, pp. 90489058, 2004.

[58] C. Holz-Schietinger and N. O. Reich, “The inherent processivity of the human de novo methyltransferase 3A (DNMT3A) is enhanced by DNMT3L," Journal of Biological Chemistry, vol. 285, no. 38, pp. 29091-29100, 2010.

[59] C. C. Kumar, "Genetic abnormalities and challenges in the treatment of acute myeloid Leukemia," Genes and Cancer, vol. 2, no. 2, pp. 95-107, 2011.

[60] E. Reboursiere, S. Chantepie, A.-C. Gac, and O. Reman, "Rare but authentic Philadelphia-positive acute myeloblastic leukemia: two case reports and a literature review of characteristics, treatment and outcome," Hematology/Oncology and Stem Cell Therapy, vol. 8, no. 1, pp. 28-33, 2015.

[61] Y. Chi, V. Lindgren, S. Quigley, and S. Gaitonde, "Acute myelogenous leukemia with $\mathrm{t}(6 ; 9)$ (p23;q34) and marrow basophilia: an overview," Archives of Pathology \& Laboratory Medicine, vol. 132, no. 11, pp. 1835-1837, 2008.

[62] T. Mercher, G. D. Raffel, S. A. Moore et al., "The OTT-MAL fusion oncogene activates RBPJ-mediated transcription and induces acute megakaryoblastic leukemia in a knockin mouse model," Journal of Clinical Investigation, vol. 119, no. 4, pp. 852864, 2009.

[63] M. Camós, J. Esteve, P. Jares et al., "Gene expression profiling of acute myeloid leukemia with translocation $\mathrm{t}(8 ; 16)(\mathrm{p} 11 ; \mathrm{p} 13)$ and MYST3-CREBBP rearrangement reveals a distinctive signature with a specific pattern of HOX gene expression," Cancer Research, vol. 66, no. 14, pp. 6947-6954, 2006.

[64] J. Borrow, A. M. Shearman, V. P. Stanton Jr. et al., “The $\mathrm{t}(7 ; 11)(\mathrm{p} 15 ; \mathrm{p} 15)$ translocation in acute myeloid leukaemia fuses the genes for nucleoporin NUP98 and class I homeoprotein HOXA9," Nature Genetics, vol. 12, no. 2, pp. 159-167, 1996.

[65] S. Gröschel, M. A. Sanders, R. Hoogenboezem et al., "Mutational spectrum of myeloid malignancies with $\operatorname{inv}(3) / t(3 ; 3)$ reveals a predominant involvement of RAS/RTK signaling pathways," Blood, vol. 125, no. 1, pp. 133-139, 2015.
[66] T. Gamou, E. Kitamura, F. Hosoda et al., "The partner gene of AML1 in $\mathrm{t}(16 ; 21)$ myeloid malignancies is a novel member of the MTG8(ETO) family," Blood, vol. 91, no. 11, pp. 4028-4037, 1998.

[67] T. Schoofs, W. E. Berdel, and C. Müller-Tidow, "Origins of aberrant DNA methylation in acute myeloid leukemia," Leukemia, vol. 28, no. 1, pp. 1-14, 2014.

[68] F. Ferrara and C. A. Schiffer, "Acute myeloid leukaemia in adults," The Lancet, vol. 381, no. 9865, pp. 484-495, 2013.

[69] H. Döhner, D. J. Weisdorf, and C. D. Bloomfield, "Acute myeloid leukemia," New England Journal of Medicine, vol. 373, no. 12, pp. 1136-1152, 2015.

[70] W.-J. Hong and B. C. Medeiros, "Unfavorable-risk cytogenetics in acute myeloid leukemia," Expert Review of Hematology, vol. 4, no. 2, pp. 173-184, 2011.

[71] A. H. Shih, O. Abdel-Wahab, J. P. Patel, and R. L. Levine, "The role of mutations in epigenetic regulators in myeloid malignancies," Nature Reviews Cancer, vol. 12, no. 9, pp. 599612, 2012.

[72] E. H. Estey, "Acute myeloid leukemia: 2013 update on riskstratification and management," American Journal of Hematology, vol. 88, no. 4, pp. 318-327, 2013.

[73] M. Higuchi, D. O’Brien, P. Kumaravelu, N. Lenny, E.-J. Yeoh, and J. R. Downing, "Expression of a conditional AML1ETO oncogene bypasses embryonic lethality and establishes a murine model of human $\mathrm{t}(8 ; 21)$ acute myeloid leukemia," Cancer Cell, vol. 1, no. 1, pp. 63-74, 2002.

[74] L. M. Kelly and D. G. Gilliland, "Genetics of myeloid leukemias," Annual Review of Genomics and Human Genetics, vol. 3, no. 1, pp. 179-198, 2002.

[75] The Cancer Genome Atlas Research Network, "Genomic and epigenomic landscapes of adult de novo acute myeloid leukemia," New England Journal of Medicine, vol. 368, no. 22, pp. 2059-2074, 2013.

[76] L. Couronné, C. Bastard, and O. A. Bernard, "TET2 and DNMT3A mutations in human T-Cell lymphoma," New England Journal of Medicine, vol. 366, no. 1, pp. 95-96, 2012.

[77] A. Akalin, F. E. Garrett-Bakelman, M. Kormaksson et al., "Base-pair resolution DNA methylation sequencing reveals profoundly divergent epigenetic landscapes in acute myeloid leukemia," PLoS Genetics, vol. 8, no. 6, Article ID e1002781, 2012.

[78] H. Hájková, J. Marková, C. Haškovec et al., "Decreased DNA methylation in acute myeloid leukemia patients with DNMT3A mutations and prognostic implications of DNA methylation," Leukemia Research, vol. 36, no. 9, pp. 1128-1133, 2012.

[79] T. J. Ley, L. Ding, M. J. Walter et al., "DNMT3A mutations in acute myeloid leukemia," The New England Journal of Medicine, vol. 363, no. 25, pp. 2424-2433, 2010.

[80] G. A. Challen, D. Sun, M. Jeong et al., "Dnmt3a is essential for hematopoietic stem cell differentiation," Nature Genetics, vol. 44, pp. 23-31, 2012.

[81] Y. Qu, A. Lennartsson, V. I. Gaidzik et al., "Differential methylation in CN-AML preferentially targets non-CGI regions and is dictated by DNMT3A mutational status and associated with predominant hypomethylation of HOX genes," Epigenetics, vol. 9, no. 8, pp. 1108-1119, 2014.

[82] A. F. T. Ribeiro, M. Pratcorona, C. Erpelinck-Verschueren et al., "Mutant DNMT3A: a marker of poor prognosis in acute myeloid leukemia," Blood, vol. 119, no. 24, pp. 5824-5831, 2012.

[83] X.-J. Yan, J. Xu, Z.-H. Gu et al., "Exome sequencing identifies somatic mutations of DNA methyltransferase gene DNMT3A in acute monocytic leukemia," Nature Genetics, vol. 43, no. 4, pp. 309-317, 2011. 
[84] R. A. Alharbi, R. Pettengell, H. S. Pandha, and R. Morgan, "The role of HOX genes in normal hematopoiesis and acute leukemia," Leukemia, vol. 27, no. 5, pp. 1000-1008, 2013.

[85] E. A. Eklund, "The role of hox proteins in leukemogenesis: insights into key regulatory events in hematopoiesis," Critical Reviews in Oncogenesis, vol. 16, no. 1-2, pp. 65-76, 2011.

[86] T. A. Paul, J. Bies, D. Small, and L. Wolff, "Signatures of polycomb repression and reduced $\mathrm{H} 3 \mathrm{~K} 4$ trimethylation are associated with p15INK4b DNA methylation in AML," Blood, vol. 115, no. 15, pp. 3098-3108, 2010.

[87] A. Yalcin, C. Kreutz, D. Pfeifer et al., "MeDIP coupled with a promoter tiling array as a platform to investigate global DNA methylation patterns in AML cells," Leukemia Research, vol. 37, no. 1, pp. 102-111, 2013.

[88] A. Mayle, L. Yang, B. Rodriguez et al., "Dnmt3a loss predisposes murine hematopoietic stem cells to malignant transformation," Blood, vol. 125, no. 4, pp. 629-638, 2015.

[89] G. Marcucci, K. H. Metzeler, S. Schwind et al., "Age-related prognostic impact of different types of DNMT3A mutations in adults with primary cytogenetically normal acute myeloid leukemia," Journal of Clinical Oncology, vol. 30, no. 7, pp. 742750, 2012.

[90] M. J. Walter, L. Ding, D. Shen et al., "Recurrent DNMT3A mutations in patients with myelodysplastic syndromes," Leukemia, vol. 25, no. 7, pp. 1153-1158, 2011.

[91] G. Genovese, S. Jaiswal, B. L. Ebert, and S. A. McCarroll, "Clonal hematopoiesis and blood-cancer risk," New England Journal of Medicine, vol. 372, pp. 1071-1072, 2015.

[92] S. Jaiswal, P. Fontanillas, J. Flannick et al., "Age-related clonal hematopoiesis associated with adverse outcomes," The New England Journal of Medicine, vol. 371, no. 26, pp. 2488-2498, 2014.

[93] C. Holz-Schietinger, D. M. Matje, and N. O. Reich, "Mutations in DNA methyltransferase (DNMT3A) observed in acute myeloid leukemia patients disrupt processive methylation," Journal of Biological Chemistry, vol. 287, no. 37, pp. 30941-30951, 2012.

[94] S. J. Kim, H. Zhao, S. Hardikar, A. K. Singh, M. A. Goodell, and T. Chen, "A DNMT3A mutation common in AML exhibits dominant-negative effects in murine ES cells," Blood, vol. 122, no. 25, pp. 4086-4089, 2013.

[95] K. H. Metzeler, A. Walker, S. Geyer et al., "DNMT3A mutations and response to the hypomethylating agent decitabine in acute myeloid leukemia," Leukemia, vol. 26, no. 5, pp. 1106-1107, 2012.

[96] D. A. Russler-Germain, D. H. Spencer, M. A. Young et al., "The R882H DNMT3A mutation associated with AML dominantly inhibits wild-type DNMT3A by blocking its ability to form active tetramers," Cancer Cell, vol. 25, no. 4, pp. 442-454, 2014.

[97] L. I. Shlush, S. Zandi, A. Mitchell et al., "Identification of pre-leukaemic haematopoietic stem cells in acute leukaemia," Nature, vol. 506, pp. 328-333, 2014.

[98] M. A. Lichtman, "Clonal hematopoiesis: a 'CHIP' off the old block," Blood, vol. 126, pp. 1-2, 2015. 


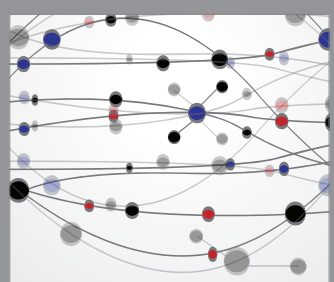

The Scientific World Journal
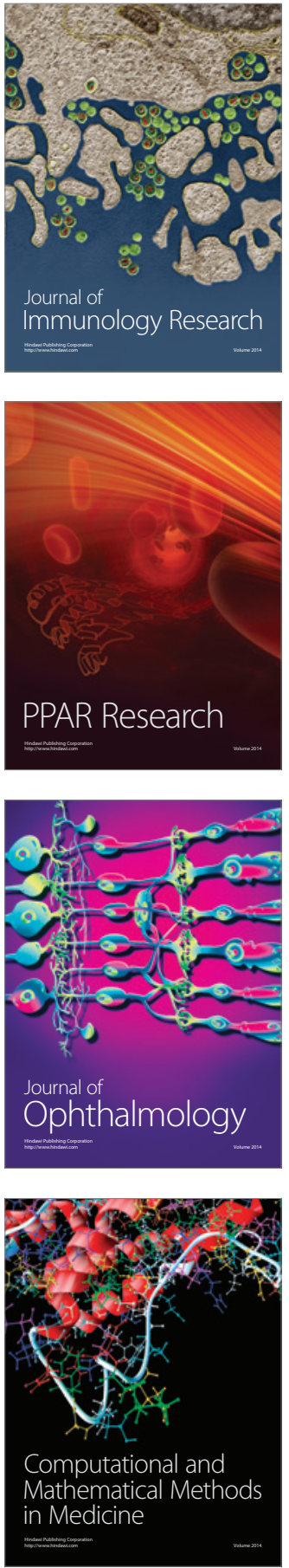

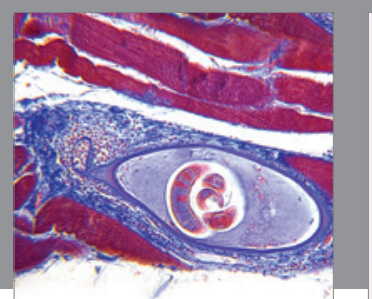

Gastroenterology Research and Practice
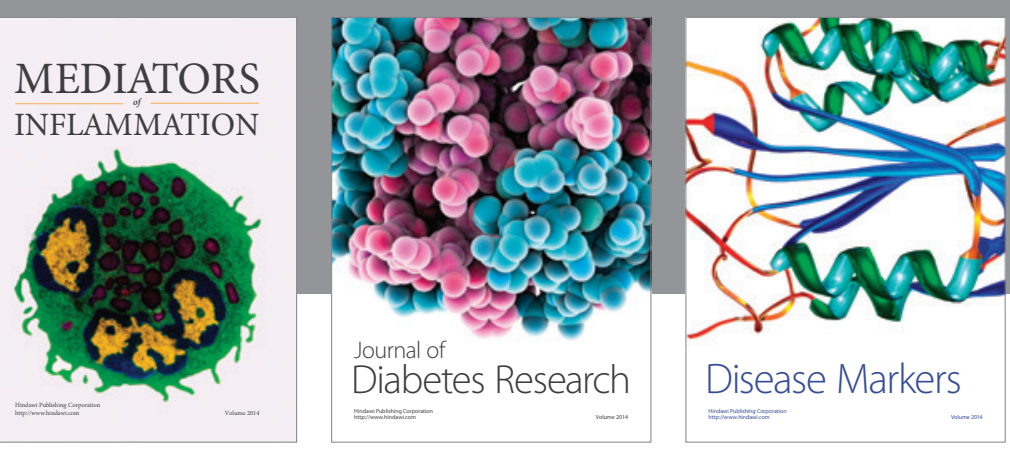

Disease Markers

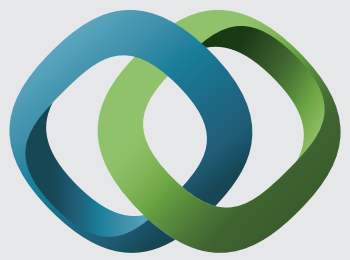

\section{Hindawi}

Submit your manuscripts at

https://www.hindawi.com
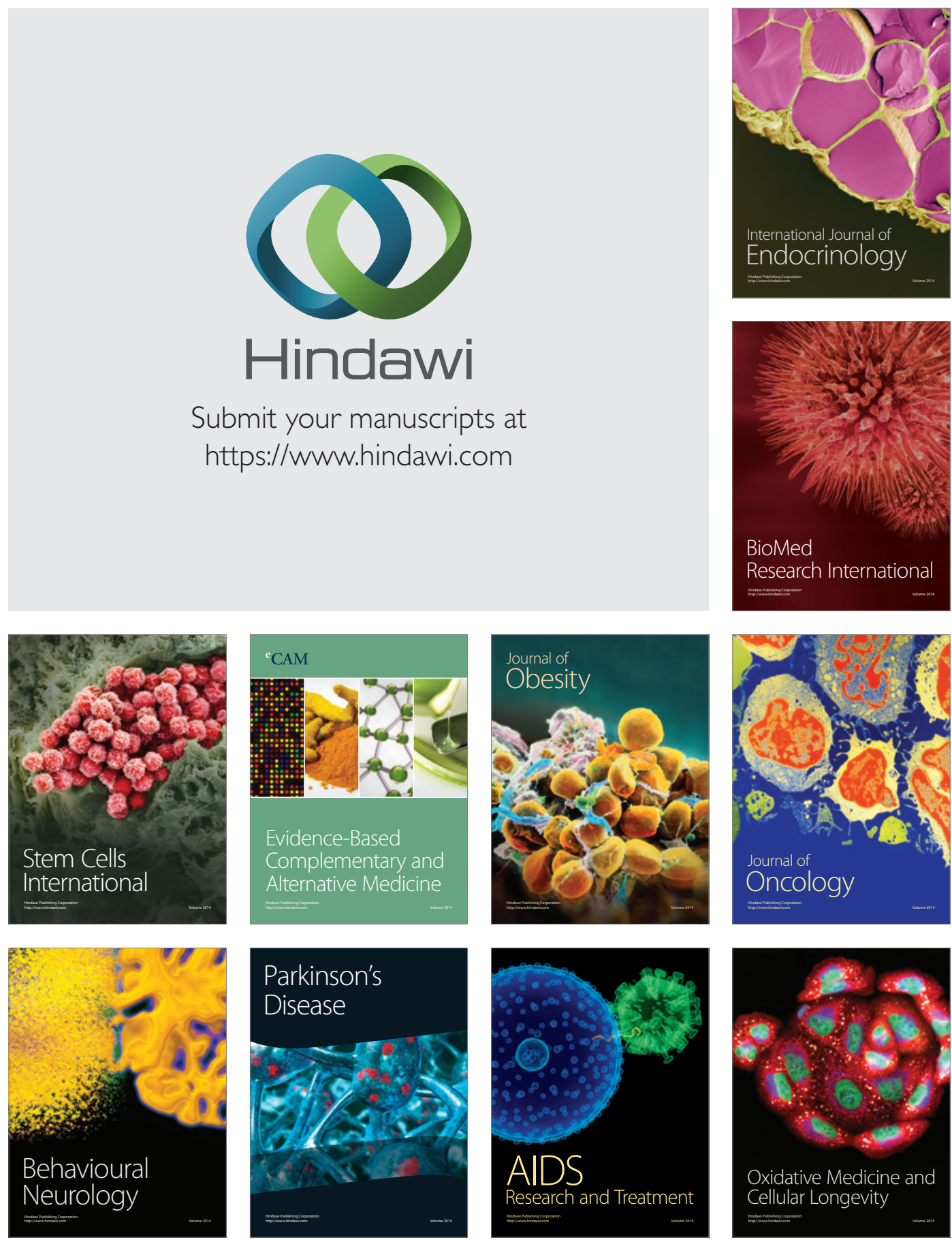